\title{
PENGARUH TIME REPETITION (TR) DAN FLIP ANGLE (FA) TERHADAP INFORMASI ANATOMI PADA 3D TOF MRA PEMERIKSAAN BRAIN DENGAN MRI 1.5 TESLA
}

\author{
Muhamad Marno Alamsyah ${ }^{1}$, Rasyid $^{2}$, Emi Murniati $^{3}$ \\ 1,2,3 Poltekkes Kemenkes Semarang, Indonesia \\ Corresponding author: Muhamad Marno Alamsyah \\ e-mail: marnoalamsyah18@gmail.com
}

\begin{abstract}
Background: In MR angiography examination of the brain, there are many clinical situations where radiologist want to optimal suppression of stasionary nuclei. So stasionary nuclei and flowing nuclei will produce a good contrast. One of the most commonly used method MR angiography of the brain is a 3D TOF because it can show the blood vessels by hyperintens with more hypointens of background. Parameters TR and flip angle is one of the parameters that will determine a stasionary nuclei experiencing suppression well and the flowing nuclei will still generate a signal that more hyperintens. The porpose of this study was to determine the influence of repetition time and flip angle of the anatomical information of 3D TOF MRA examination of the brain, and also to determine value the repetition time and flip angle best to display anatomical information of 3D TOF MRA examination of the brain.

Methods: This research is an experimental approach to the pre-experimental research design and post-test only research design. This research was conducted in Bintaro Premier Hospital. The data in the form of 54 3D TOF MRA images brain of 6 volunteers with nine variations repetitions time and flip angle. Assessment anatomical information performed by the two respondents or reviewer. The data analysis is done by testing the influence is multiple linear regression to determine the value of repetition time and flip angle optimal use friedman mean rank test.

Result: The result showed that there is the influence of repetition time and flip angle of the anatomical information on 3D TOF MRA examination of the brain with a significance level of $\mathrm{p}<0.001$ ( $\mathrm{p}<0.05)$. The repetition time $30 \mathrm{~ms}$ and flip angle $30^{\circ}$ is and optimal value for anatomical information showing 3D TOF MRA examination of the brain. application of repetition time $30 \mathrm{~ms}$ and flip angle $30^{\circ}$ can be properly saturate or suppression the stasionary nuclei so that is displays excellent contrast between the nuclei.

Conclution: There are influence of repetition time and flip angle to the anatomical information on 3D TOF MRA examination of the brain with a significance level of $\mathrm{p}<0.001(\mathrm{p}<0.05)$. The repetition time $30 \mathrm{~ms}$ and a flip angle of $30^{\circ}$ is an optimal value for anatomical information showing 3D TOF MRA examination of the brain.
\end{abstract}

Keywords: Repetition time, flip angle, 3D TOF MRA examination of the brain, stasionary nuclei and flowing nuclei.

\section{Pendahuluan}

Magnetic Resonance angiography adalah pemeriksaan Radiografi yang bertujuan untuk memperlihatkan atau mengevaluasi pembuluh darah dengan menggunakan modalitas MRI.

Dalam pemeriksaan MR angiografi ada banyak metode yang dapat digunakan. Hal ini dilakukan karena seiiring dengan perkembangan kelainan - kelainan yang ada pada pembuluh darah terutama pada daerah otak baik itu berupa aneurisma atau stenosis dan yang yang lainnya. Metode - metode tersebut adalah digital subtraction on MR angiography (DS - MRA), time of flight MR angiography (TOF - MRA), phase contrast MR angiography (PC - MRA) dan contrast enhanced MRA (CE - MRA) (Westbrook, 2011).

Metode yang digunakan pada penelitian ini adalah Time Of Flight (TOF), dimana teknik TOF ini menggunakan variasi dari akuisisi incohernt gradient echo yang dikombinasikan dengan gradient moment rephasing untuk menghasilkan sinyal tinggi (high signal) dalam nukleus flowing (aliran pembuluh darah). Kontras vaskular dimaksimalkan dengan meningkatkan sinyal flowing nukleus dan mensupresi sinyal dari nukleus stasioner (Westbrook, 2011). 
Metode TOF, time repetition dan flip angle dipilih sehingga nukleus stasioner tersaturasi sementara flowing nukleus pada kejadian inflow effect (flow entry fenomena) magnetisasi akan tetap fresh dan menghasilkan high signal pada pembuluh darah. Penggunaan time repetition dan flip angle yang sesuai pada metode TOF akan menghasilkan citra pembuluh hyperintens dan nukleus stasioner yg hypointens karena tersaturasi dan kontras yang baik diantara kedua nukleus tersebut. Namun, jika time repetition (TR) terlalu singkat maka flowing nukleus akan susah untuk recovery ke longitudinal magnetisasi yang menyebabkan flowing nukleus akan ikut tersupresi bersama nukleus stasioner. Jika TR yang digunakan terlalu panjang juga akan berakibat buruk terhadap kejelasan citra, karena dengan TR yang panjang maka nukleus stasioner akan mendapatkan waktunya untuk recoveri ke longitudinal. (Lombardi, 2004)

Menurut mukherjee (2007) penggunaan TR yang singkat memungkinkan waktu yang sangat terbatas untuk recovery magnetisasi longitudinal sebelum pulsa eksitasi berikutnya. Dengan menggunakan flip angle yang besar untuk eksitasi, akan sangat sedikit magnetisasi transversal untuk menghasilkan sinyal. Disisi lain, penggunaan RF pulsa dengan flip angle yang besar akan mengasilkan suppresi atau penekanan yang lebih baik pada jaringan stasioner dan sinyal yang lebih besar dari pembuluh darah. Maka, TR dan flip angle harus tepat.

Tujuan dari penelitian ini adalah untuk mengetahui pengaruh dari time repetition (TR) dan flip angle (FA) terhadap informasi anatomi pada pemeriksaan 3D TOF MRA brain. selain itu bertujuan untuk mengetahui nilai dari time repetition (TR) dan flip angle (FA) yang optimal untuk pemeriksaan 3D TOF MRA brain.

\section{Metode}

Jenis penelitian yang digunakan pada Tugas Akhir ini adalah jenis penelitian eksperimen dengan rancangan penelitian pre eksperimen dan menggunakan desain penelitian post test only. Penelitian ini bertujuan untuk mengetahui pengaruh setelah dilakukan perubahan nilai - nilai TR dan flip angle terhadap informasi anatomi pada pemeriksaan 3D TOF MRA brain dengan MRI 1.5 Tesla.

Enam (6) orang sukarelawan pemeriksaan 3D TOF MRA brain di Instalasi Radiologi Rumah Sakit Premier Bintaro sebagai sample penelitian. Populasi penelitian adalah pemeriksaan MRA brain yang menggunakan 3D
TOF di Instalasi Radiologi Rumah Sakit Premier Bintaro selama satu bulan Oktober 2016 kemudian dihitung dengan teknik sampling menggunakan rumus sloven (Notoatmodjo, 2010). Responden atau Reviewer yang memberikan penilaian terhadap citra variasi TR dan flip angle pada pemeriksaan 3D TOF MRA brain adalah 1 (satu) orang Dokter spesialis Radiologi dan 1 orang Radiolog sebagai parameter konsistensi subjektifitas Reviewer.

Prosedur dalam penelitian ini adalah :

1. Sukarelawan diberi informed consent tentang maksud dan tujuan penelitian serta diberi penjelasan tentang prosedur pemeriksaan, serta diyakinkan bahwa penelitian ini tidak berbahaya bagi mereka.

2. Pembuatan citra MRA brain diawali dengan membuat 3 plane localizer

3. Dilakukan pembuatan citra MRA brain dengan sekuens 3D TOF GRE

4. Setiap sukarelawan dilakukan scanning dengan 9 variasi TR dan flip angle yaitu; FA $20^{\circ}-$ TR 30, FA $20^{\circ}$ - TR 40, FA $20^{\circ}$ - TR 50, FA $25^{\circ}-$ TR 30, FA $25^{\circ}-$ TR 40, FA $25^{\circ}-$ TR 50 , FA $30^{\circ}-$ TR 30, FA $30^{\circ}$ - TR 40, FA $30^{\circ}$ - TR 50.

5. Citra hasil penelitian tersebut disimpan dalam CD dengan format DICOM tanpa ada keterangan identitas apapun, hanya diberikan kode serial citra.

6. Dua orang Dokter spesialis Radiologi yang berpengalaman di bidang MRI 1.5 T khususnya pemeriksaan MRA brain dimohon untuk mencermati citra dari masing - masing citra. Penilaian kualitatif berupa menilai kontras citra secara umum, internal carotid arteri, anterior cerebral arteri, middle cerebral arteri, posterior cerebral arteri, vertebral arteri, basilar arteri, serta memilih citra terbaik dari 9 variasi TR dan flip angle tersebut.

7. Penilaian Dokter spesialis Radiologi dilakukan dengan memberikan skor 1, 2, dan 3 pada kuisioner yang telah disediakan. Pertanyaan tentang kejelasan citra diberikan Skor 3 berarti "sangat jelas" diberikan apabila anatomi MRA brain yang diamati batas - batas antara pembuluh darah dan organ sekitar terlihat sangat jelas kemudian pembuluh darah terlihat sangat terang, Skor 2 berarti "cukup jelas" diberikan apabila anatomi MRA brain yang diamati batas - batas antara pembuluh darah dan organ sekitar terlihat cukup jelas kemudian pembuluh darah terlihat cukup terang, Skor 1 berarti "tidak jelas" 
diberikan apabila anatomi MRA brain yang diamati batas - batas antara pembuluh darah dan organ sekitar terlihat tidak jelas kemudian pembuluh darah terlihat tidak terang.

Data dari hasil skor penilaian Reviewer merupakan data ordinal, data ini dikonversi menjadi data rasio menggunakan methode successive interval (MSI) agar bisa dilakukan uji regresi linier berganda. Kemudian data diolah dan dianalisa secara statistika dengan menggunakan software SPSS 17.0. uji regresi linier dilakukan bertujuan untuk mengetahui ada atau tidaknya pengaruh, kuat dan besar pengaruh. Untuk menentukan nilai TR dan flip angle yang optimal dilakukan uji friedman rank test.

\section{Hasil dan Pembahasan}

Penelitian dilakukan terhadap 6 (enam) sukarelawan berjenis kelamin laki - laki dan perempuan, rentang usia $20-23$ tahun.

Tabel 1. Karakteristik sukarelawan berdasarkan jenis kelamin

\begin{tabular}{ccc}
\hline Jenis Kelamin & Jumlah & Persentase \\
\hline Laki - Laki & 4 & $66,7 \%$ \\
Perempuan & 2 & $33,7 \%$ \\
\hline Total & 6 & $100 \%$ \\
\hline
\end{tabular}

Dari ke enam sukarelawan tersebut diperoleh informasi anatomi 3D TOF MRA brain. setiap sukarelawan dilakukan 9 variasi dan menghasilkan 54 citra yang dapat menampakkan anatomi internal carotid arteri, anterior cerebral arteri, middle cerebral arteri, posterior cerebral arteri, vertebral arteri, dan basilar arteri.

Sebelum dilakukan uji statistik untuk mengetahui pengaruh TR dan flip angle terhadap informasi anatomi pemeriksaan 3D TOF MRA brain, dilakukan pengujian kappa untuk mengetahui kesesuaian atau kesamaan persepsi reviewer dalam penilaian kuisioner. Hasil pengujian kappa terhadap 2 responden sebagai berikut :

Tabel 2. Hasil uji kappa pada dua Reviewer

\begin{tabular}{ccc}
\hline $\begin{array}{c}\text { Variasi flip angle (FA) dan } \\
\text { time repetition }(\mathrm{TR})\end{array}$ & Kappa value & $\begin{array}{c}\text { Approx } \\
\text { sig }\end{array}$ \\
\hline FA 20 dan TR 30 & 0,829 & 0,000 \\
FA 20 dan TR 40 & 0,832 & 0,000 \\
FA 20 dan TR 50 & 0,833 & 0,000 \\
FA 25 dan TR 30 & 0,816 & 0,000 \\
FA 25 dan TR 40 & 0,906 & 0,000
\end{tabular}

\begin{tabular}{lll} 
FA 25 dan TR 50 & 0,850 & 0,000 \\
FA 30 dan TR 30 & 0,842 & 0,000 \\
FA 30 dan TR 40 & 0,888 & 0,000 \\
FA 30 dan TR 50 & 0,857 & 0,000 \\
\hline
\end{tabular}

Berdasarkan hasil uji kappa dapat dilihat value kappa pada keseluruhan lebih dari 0,8, hasil ini menunjukan bahwa ada kesesuaian atau persamaan persepsi antara kedua reviewer dalam menilai informasi anatomi pemeriksaan 3D TOF MRA pada keseluruhan variasi TR dan flip angle.

Selanjutnya untuk uji pengaruh menggunakan uji regresi linier berganda. Uji regresi dilakukan dua tahap, yang pertama untuk mengetahui pengaruh TR dan flip angle terhadap informasi anatomi 3D TOF MRA brain secara keseluruhan dan yang kedua uji regresi dilakukan pada setiap organ anatomi MRA brain.

Tabel 3. Hasil uji regresi secara keseluruhan

\begin{tabular}{ccc}
\hline $\mathrm{R}$ & Adjusted $\mathrm{R}$ square & $\mathrm{Sig}$ \\
\hline 0,862 & 0,732 & $<0,001$ \\
\hline
\end{tabular}

Uji statistik regresi menghasilkan nilai signifikansi $p$ value $<0,05$ yang berarti ada pengaruh signifikan pada pemberian variasi nilai TR dan flip angle terhadap informasi anatomi pada pemeriksaan 3D TOF MRA brain. Nilai adjusted $R$ square bermakna 73,2 \% informasi anatomi pemeriksaan 3D TOF MRA brain dipengaruhi oleh TR dan flip angle dan sisanya dipengaruhi oleh faktor lain. nilai $\mathrm{R}$ menunjukan koefisien korelasi yang sangat kuat antara TR dan flip angle terhadap informasi anatomi.

Untuk mengetahui nilai TR dan flip angle yang mempunyai informasi anatomi paling optimal secara keseluruhan menggunakan uji friedman mean rank test

Tabel 4. Hasil uji friedman mean rank test keseluruhan

\begin{tabular}{cc}
\hline Variasi & Mean rank \\
\hline FA20_TR30 & 4.58 \\
FA20_TR40 & 2.46 \\
FA20_TR50 & 2.64 \\
FA25_TR30 & 6.08 \\
FA25_TR40 & 5.44 \\
FA25_TR50 & 4.51 \\
FA30_TR30 & 8.01 \\
FA30_TR40 & 5.83 \\
FA30_TR50 & 5.43 \\
\hline
\end{tabular}

Berdasarkan mean rank yang dihasilkan variasi TR $30 \mathrm{~ms}$ dan flip angle $30^{\circ}$ memperoleh nilai terbesar yaitu 8,01 dibanding dengan yang lainnya, maka dapat 
dinyatakan variasi TR $30 \mathrm{~ms}$ dan flip angle $30^{\circ}$ lebih optimal memberikan citra anatomi 3D TOF MRA brain.

Uji regresi linier berganda setiap kriteria anatomi dilakukan untuk mengetahui pengaruh setiap kriteria dalam sebuah citra. Hasil uji regresi linier berganda setiap kriteria anatomi dapat dilihat pada tabel 5.

Tabel 5 hasil uji regresi linier berganda setiap kriteria anatomi

\begin{tabular}{lccc}
\hline \multicolumn{1}{c}{$\begin{array}{c}\text { Informasi } \\
\text { Anatomi }\end{array}$} & $\mathrm{R}$ & $\begin{array}{c}\text { Adjusted } \\
R \text { square }\end{array}$ & $\mathrm{Sig}$ \\
\hline $\begin{array}{l}\text { Internal carotid } \\
\text { arteri }\end{array}$ & 0,499 & 0,220 & 0,000 \\
$\begin{array}{l}\text { Anterior } \\
\text { cerebral arteri }\end{array}$ & 0,738 & 0,527 & 0,000 \\
$\begin{array}{l}\text { Middle cerebral } \\
\text { arteri }\end{array}$ & 0,643 & 0,391 & 0,000 \\
$\begin{array}{l}\text { Posterior } \\
\text { cerebral arteri }\end{array}$ & 0,854 & 0,719 & 0,000 \\
$\begin{array}{l}\text { Vertebral arteri } \\
\text { Basilar arteri }\end{array}$ & 0,726 & 0,509 & 0,000 \\
\hline
\end{tabular}

Terdapat hubungan yang sedang dan signifikan antara TR dan flip angle terhadap internal carotid arteri. Ada pengaruh yang signifikan variasi TR dan flip angle terhadap internal carotid arteri dan $22 \%$ internal carotid arteri dipengaruhi TR dan flip angle sisanya dipengaruhi oleh faktor lain.

Terdapat hubungan yang kuat dan signifikan antara TR dan flip angle terhadap anterior cerebral arteri. Ada pengaruh yang signifikan variasi TR dan flip angle terhadap anterior cerebral arteri dan 52,7 \% anterior cerebral arteri dipengaruhi TR dan flip angle sisanya dipengaruhi oleh faktor lain.

Terdapat hubungan yang kuat dan signifikan antara TR dan flip angle terhadap middle cerebral arteri. Ada pengaruh yang signifikan variasi TR dan flip angle terhadap middle cerebral arteri dan 39,1 \% middle cerebral arteri dipengaruhi TR dan flip angle sisanya dipengaruhi oleh faktor lain.

Terdapat hubungan yang sangat kuat dan signifikan antara TR dan flip angle terhadap posterior cerebral arteri. Ada pengaruh yang signifikan variasi TR dan flip angle terhadap posterior cerebral arteri dan 71,9\% posterior cerebral arteri dipengaruhi TR dan flip angle sisanya dipengaruhi oleh faktor lain.

Terdapat hubungan yang kuat dan signifikan antara TR dan flip angle terhadap vertebral arteri. Ada pengaruh yang signifikan variasi TR dan flip angle terhadap vertebral arteri dan $50,9 \%$ vertebral arteri dipengaruhi TR dan flip angle sisanya dipengaruhi oleh faktor lain.

Terdapat hubungan yang kuat dan signifikan antara TR dan flip angle terhadap basilar arteri. Ada pengaruh yang signifikan variasi TR dan flip angle terhadap basilar arteri dan 47,9\% basilar arteri dipengaruhi TR dan flip angle sisanya dipengaruhi oleh faktor lain.

Untuk mengetahui nilai TR dan flip angle yang mempunyai informasi anatomi paling optimal setiap organ menggunakan uji friedman mean rank test.

Tabel 6. Hasil uji friedman mean rank test per organ

\begin{tabular}{lcccccc}
\hline \multirow{2}{*}{ Variasi FA dan TR } & \multicolumn{7}{c}{ Informasi anatomi } \\
\cline { 2 - 7 } & ICA & ACA & MCA & PCA & VA & BA \\
\hline FA 20 DAN TR 30 & 4,67 & 5,50 & 5,00 & 3,33 & 4,25 & 4,75 \\
FA 20 DAN TR 40 & 3,17 & 2,33 & 1,92 & 2,00 & 3,17 & 2,17 \\
FA 20 DAN TR 50 & 3,17 & 1,67 & 2,83 & 2,00 & 3,17 & 3,00 \\
FA 25 DAN TR 30 & 5,42 & 5,67 & 6,50 & 6,08 & 6,33 & 6,50 \\
FA 25 DAN TR 40 & 6,17 & 5,67 & 5,08 & 6,08 & 4,25 & 5,42 \\
FA 25 DAN TR 50 & 4,67 & 5,08 & 4,33 & 4,67 & 4,25 & 4,08 \\
FA 30 DAN TR 30 & 7,67 & 8,42 & 7,17 & 8,67 & 8,42 & 7,75 \\
FA 30 DAN TR 40 & 4,67 & 5,00 & 6,42 & 6,08 & 6,33 & 6,50 \\
FA 30 DAN TR 50 & 5,42 & 5,67 & 5,75 & 6,08 & 4,83 & 4,83 \\
\hline
\end{tabular}

Berdasarkan hasil uji friedman mean rank test dihasilkan variasi TR $30 \mathrm{~ms}$ dan flip angle $30^{\circ}$ memperoleh nilai terbesar, maka dapat dinyatakan variasi tersebut lebih optimal memberikan citra anatomi 3D TOF MRA brain.

Pembahasan

Pemilihan TR dan flip angle menjadi salah satu parameter yang dapat mempengaruhi agar citra optimal pada pemeriksaan 3D TOF MRA brain. Ada dua nukleus dengan sifat berbeda yang akan menjadi pengaruh pemilihan TR dan flip angle yaitu nukleus stasioner dan nukleus flowing. Pemilihan nilai TR dan flip angle yang tepat dapat membantu Radiolog untuk menginterpretasi citra secara tepat dan akurat. Hasil uji pengaruh pada penelitian ini menunjukan nilai $p$ value $<0,001$ ( $p<$ $0,05)$ yang berarti ada pengaruh TR dan flip angle terhadap informasi anatomi pada pemeriksaan 3D TOF MRA brain. Variasi TR $30 \mathrm{~ms}$ dan flip angle $30^{\circ}$ dinyatakan sebagai variasi yang lebih optimal dalam menampilkan citra informasi anatomi 3D TOF MRA brain. karakteristik masing - masing variasi menimbulkan pengaruh yang signifikan secara statistik 
apabila ditinjau dari kemampuan semua variasi melakukan supresi terhadap nukleus stasioner.

MRA berfungsi sebagai catatan fisiologi untuk aliran darah. Jika ada gangguan pada pola aliran darah seperti yang umumnya terjadi yaitu stenosis pada pembuluh darah, maka turbulensi dapat dicatat sebagai daerah dimana sinyal vaskular berkurang atau bahkan hilang. (Lee, 2001)

Time of flight (TOF) Salah satu sekuens yang digunakan dan dianggap efesien dalam pemeriksaan MRA. TOF menghasilkan kontras vaskular dengan memanipulasi longitudinal magnetisasi nukleus stasioner. TOF menggunakan incoherent gradient echo pulsa sekuens yang dikombinasikan dengan gradient moment rephasing untuk enhancement pada aliran. (Westbrook, 2011)

Metode TOF pada MRA dapat ditingkatkan dengan 2D (slice by slice) atau 3D (volume) mode akuisisi. Umumnya, TOF diakuisisi dengan 3D sehingga lebih optimal untuk mendapatkan resolusi tinggi dan untuk evaluasi pembuluh darah kecil dengan kecepatan pembuluh darah tinggi seperti pembuluh intracranial (circle of willis). (Westbrook,2011)

Pemilihan TR dan flip angle salah satu parameter yang dapat mempengaruhi agar citra lebih optimal. Penggunaan TR yang singkat memungkinkan waktu yang sangat terbatas untuk recovery ke magnetisasi longitudinal sebelum pulsa eksitasi berikutnya. Flip angle yang besar untuk eksitasi, akan sangat sedikit magnetisasi transversal untuk menghasilkan sinyal. Disisi lain, penggunaan pulsa radiofrekuensi dengan flip angle yang besar akan menghasilkan supresi yang lebih baik pada jaringan stasioner. (Mukherjee, 2007)

Nilai TR dan flip angle menjadi salah satu faktor penting untuk menghasilkan citra yang baik pada pemeriksaan MRA. Karena setiap kenaikan nilai flip angle maka sudut balik nukleus untuk recovery semakin lama kemudian ketika diberikan TR yang singkat maka nukleus stasioner akan menerima pulsa RF yang berulang sehingga akan tersupresi dan tidak menghasilkan sinyal maka citra yang dihasilkan akan hypointens. Oleh karena itu ketajaman atau kontras antara pembuluh darah dengan organ sekitar akan sangat baik ketika nukleus stasioner tersupresi dengan baik juga.

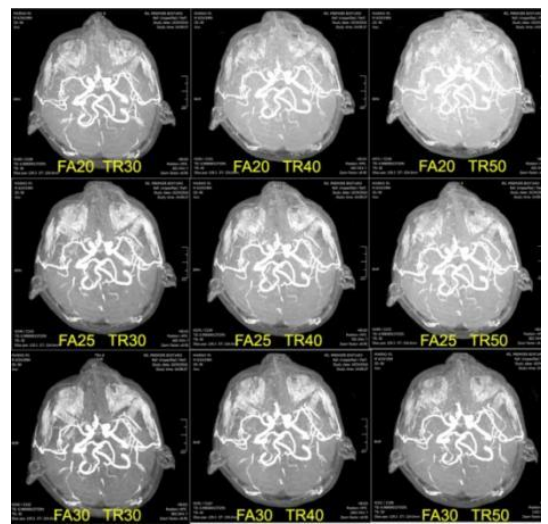

Gambar 1. Citra 3D TOF MRA brain dengan 9 (sembilan) variasi TR dan flip angle

Ketika TR yang digunakan lebih panjang maka nukleus stasioner akan mendapatkan waktunya untuk recovery lalu menghasilkan sinyal. Begitu pun ketika flip angle yang digunakan lebih kecil maka akan lebih mudah nukleus untuk recovery ke longitudnal dan menghasilkan sinyal. Jika nukleus stasioner menghasilkan sinyal maka akan berakibat buruk terhadap kontras gambaran.

Hal ini yang menjadikan nilai TR yang singkat dan flip angle besar lebih unggul dibanding dengan variasi yang lainnya. TR adalah pemberian pulsa RF satu ke pemberian RF berikutnya ketika waktu pemberian pulsa tersebut dipersingkat maka nukleus stasioner tidak cukup waktu untuk recovery menghasilkan sinyal sehingga akan tersupres. Flip angle adalah ukuran sudut yang menentukan seberapa banyak magnetisasi longitudinal yang dirubah menjadi transversal. Ketika flip angle yang gunakan lebih besar maka suatu nukleus untuk recovery semakin lama kemudian diberikan TR yang singkat, maka nukleus tersebut akan tersupresi.

\section{Simpulan}

Ada pengaruh TR dan flip angle terhadap informasi anatomi pada pemeriksaan 3D TOF MRA brain dengan $p$ value $<0,001(p<0,05)$. Nilai TR dan flip angle yang mempunyai informasi anatomi lebih optimal pada pemeriksaan 3D TOF MRA brain yaitu TR $30 \mathrm{~ms}$ dan flip angle $30^{\circ}$.

Direkomendasikan penggunaan TR $30 \mathrm{~ms}$ dan flip angle $30^{\circ}$ sebagai parameter untuk pemeriksaan $3 \mathrm{D}$ TOF MRA brain. 


\section{Daftar Pustaka}

Atlas, W, Scot, Magnetic Resonance Imaging of the Brain and Spine, Fourth Edition, Volume One, Lippincott and Wilkins a Wolters KIuwer Bussiner. Philadelphia, 2009

Brown, Mark A. Semelka, Richard C, MRI: Basic Principles and Applications, third Edition, Wiley-Blackwell, Amerika Serikat, 2010

Carr, C James. Carroll, J Timothy, Magnetic Resonance Angiography, Principles and Aplication. Springer. New York Dordrecht London, 2012

Dahlan, Sopiyudin M, Statistik Untuk Kedokteran Dan Kesehatan. Epidemiologi Indonesia, Jatinagor, 2014

Dahlan, Sopiyudin M Regresi Linear Disertai Praktik Dengan SPSS. Epidemiologi Indonesia, Jatinagor, 2012

Kartawiguna, Daniel, Tomografi Resonansi Magnetik inti, Graha Ilmu, Yogyakarta, 2015

Lombardi, Massimo. Bartolozzi, Carlo MRI Of The Heart And Vessels. Springer, Verlay Italia, Milan, 2004

Mukherjee, Debabrata. Rajagopalan, Sanjay $C T$ and $M R$ Angiography of The Peripheral Circulation, Practical Approach With Clinical Protocol. Informa, United Kingdom, 2007

Notoatmojo, Soekidjo, Metodologi Penelitian Kesehatan, Rineka Citra, Jakarta, 2010

Pearce, C Evelyn Anatomi dan Fisiologi Untuk Paramedis, Gramedika Pustaka Utama. Jakarta, 2002

Ramlho Joana, Castillo Mauricio Vascular Imaging of the Central Nervous System: Physical Principles, Clinical Applications, and Emerging Technique. John Wiley and Sons. Hoboken, 2014

Riwidikdo, Handoko Statistik untuk Penelitian Kesehatan dengan Aplikasi Program R dan SPSS. Pustaka Rihama. Yogyakarta, 2010

Schneider G, Prince. M. R, meaney J.F.M, and Ho V.B, Magnetic Resonance Angiography, Technique Indication and Practical Application. Springer Milan Berlin Heidelberg New York, 2005

Dahlan, Sopiyudin, Regresi Linier Disertai Praktik Dengan SPSS. Epidemiologi Indonesia. Jakarta, 2012

Syaifuddin, Anatomi Fisiologi Untuk Mahasiswa Keperawatan. EGC. Jakarta, 2006

Viera J, Anthony. Garrett M, Joanne, Understanding Interobserver Agreement: The kappa Statistic. Research Series, 2005

Westbrook, Catherine, Handbook Of MRI Technique Third Edition, Wiley Blackwell Science Ltd, 2008

Westbrook Catherine, Kaut Caroline, MRI In Practice 4th Edition, Wiley Blackwell Science Ltd, 2011

Woodward, peggy and william, W. amison MRI Optimization, a hand on approach, McGraw-Hill, Co. USA, 1997

Woodward, peggy, MRI for technologist, McGraw-hill, inc, USA,

2001 